\title{
Quantitative characterization of polyacrylamide-shale interaction under various saline conditions
}

\author{
Samyukta Koteeswaran $^{1}$ Jack C. Pashin ${ }^{2} \cdot$ Josh D. Ramsey $^{1} \cdot$ Peter E. Clark $^{1}$
}

Received: 15 September 2016/Published online: 22 June 2017

(c) The Author(s) 2017. This article is an open access publication

\begin{abstract}
Interaction of polymer-containing injected fluids with shale is a widely studied phenomenon, but much is still unknown about the interaction of charged polyacrylamides such as anionic and cationic polyacrylamides with shale. The nature of interaction of charged polyacrylamides with shale is not well understood, especially from the perspective of assessing the potential for polyacrylamides to cause formation damage. Zeta potential and rheological measurements were made for Chattanooga and Pride Mountain shales suspended in polyacrylamide solutions with and without inorganic salts and tetramethyl ammonium chloride (TMAC). The change in zeta potential and viscosity with time was recorded. The magnitude of decrease in the absolute value of zeta potential with time is indicative of adsorption of polymer on the surface of shale and serves as a measure of the extent of polymer interaction with shale. The salts that were used in this study are potassium chloride $(\mathrm{KCl})$, sodium chloride $(\mathrm{NaCl})$. This study quantified the interaction of anionic and cationic polyacrylamide with different North American shales. From the experimental results, it was determined that the polyacrylamides can interact strongly with shale, particularly the cationic polyacrylamide. The objective of this study was to determine the extent of interaction of anionic and cationic polyacrylamide with each shale sample in the presence of additives such as salts.
\end{abstract}

Peter E. Clark

peter.clark@okstate.edu

1 School of Chemical Engineering, Oklahoma State University, Stillwater, OK 74078, USA

2 Boone Pickens School of Geology, Oklahoma State University, Stillwater, OK 74078, USA

Edited by Xiu-Qin Zhu
Keywords Anionic and cationic polyacrylamides . Chattanooga shale $\cdot$ Pride Mountain shale $\cdot$ Zeta potential . Slurry rheology

\section{Introduction}

Interaction of injected fluids such as drilling, fracturing and completion fluids with shale has been a problem for many decades in the oil field, and shale constitutes $75 \%$ of all the formations drilled by the oil and gas industry (Khodja et al. 2010). Over the years, many studies have been conducted to quantify shale-fluid interaction and also to minimize this interaction. Interactions between shale and injected fluids are of concern for a variety of reasons. The interaction of injected fluids with shale leads to wellbore instability (Tan et al. 1996; Yu et al. 2003; Muniz et al. 2005), and the productivity of the wells decreases due to this instability, which also increases the drilling cost (Lal 1990; Mahto and Sharma 2004). Water-based mud (WBM) is the most commonly used type of drilling fluid, and shale is highly sensitive to the additives and the clays present in the WBM (Gomez and $\mathrm{He}$ 2012; He et al. 2014). The common additives used in WBM are friction reducers, acids, gellants, crosslinkers, clay controlling agents and other polymers (Harris 1988; Aften and Watson 2009). It is important to use all the necessary additives in injected fluids, but it is also equally important to use additives that do not potentially weaken the shale.

The way shale interacts with the injected fluid depends on shale properties, such as mineralogy, rock mechanical properties, porosity, clay composition and permeability, as well as the properties of injected fluids such as ionic strength and salt concentration (Gomez and He 2012; Lal 1990; Horsrud et al. 1998). Clay in shale has a great 
influence on the chemical and mechanical properties of shale. Clay minerals have a tendency to absorb water and cause an increase in the swelling pressure-a phenomenon called hydration, and this is attributed to the hydrophilic surface of the clay (Lu 1988). The clay minerals present in shale are mostly classified into five categories: montmorillonite, illite, smectite, kaolinite and attapulgite (van Olphen 1977; Luckham and Rossi 1999). The presence of abundant clay minerals changes the interaction properties of the shale with injected fluids, and the composition of the clay affects reactivity, with montmorillonitic clay being highly prone to swelling and high crystalline illite being less prone to swelling.

Much research is being conducted to study the rock mechanics to understand the interaction of shale with fluids. Conventional techniques such as dispersion and swelling tests do not fully reveal the effects of polymer-shale interaction. Studies such as pressure transmission tests are carried out to measure the effect of anions, cations and salts present in injected fluid that affect shale-fluid interaction (van Oort et al. 1995; Ghassemi and Diek 2003). The presence of ions in injected fluid alters the membrane efficiency of shale, thereby influencing ion transport from the fluid to the shale that causes the shale to swell/disperse (Zhang, et al. 2006; Mody and Hale 1993; van Oort 2003; Al-Bazali 2005).

High molecular weight polyacrylamides are commonly used friction reducers in hydraulic fracturing of shale formations. The large volumes of friction reducers (liquid volumes can be as high as four million gallons for one well), especially synthetic polymers such as polyacrylamides, are difficult to break and are proven to form membranes over shales and are associated with causing fracture and formation damage (Carman and Cawiezel 2007). Formation damage caused by the adsorption of polyacrylamides on the shale surface alters the surface properties. In this work, the study of the shale-polyacrylamide interaction focused on the extent to which polyacrylamides adhering to the shale can potentially cause formation damage.

Some of the commonly used methods such as swelling and dispersion tests do not give a true representation of the shale-fluid interaction and are qualitative in nature. Other sophisticated methods such as the autonomous triaxial and high-pressure triaxial tests can give a good quantitative measure of shale-fluid interaction by measuring the axial load, sample deformation, cell and pore pressures, but they are tedious and intensive processes (Mody et al. 2002). Hence, a simple testing method was devised that can produce reproducible semiquantitative data, which will aid in better understanding the interaction of different fluids and their components with shale.
One such method that was devised to probe the polymer-shale interaction is by rheological measuring the interactions. The rheology of shale slurries suspended in the polymer was analyzed. The factors that affect the rheology of the particle suspension are concentration, particle shape, interactions among particles, and interaction between particles and the bulk fluid (Mueller et al. 2010). Characterizing the interaction between the particle and the bulk fluid is the key to the research. When shale particles interact strongly with the bulk fluid, viscosity increases with increasing polymer concentration. This is used as a measure of the interaction of bulk fluid with shale particles. Additionally, the polymer tends to adsorb on the surface of the shale. Rheological methods were used in this work to assess the interaction of anionic and cationic polyacrylamide with samples of North American shale, the Pride Mountain shale and the Devonian-age Chattanooga shale. The interaction of shale with anionic and cationic polyacrylamide was studied rheologically by a series of flow ramps.

The second method uses zeta potential measurements over time to quantify polymer-shale interaction. The zeta potential is an electric potential developed at the solidliquid interface due to the relative movement of solid particles in water (Vane and Zang 1997). Zeta potential at the solid-liquid interface is an indirect measure of solidliquid interactions (Menon and Wasan 1987b; Werner et al. 2001; Petersen and Saykally 2008). The electrokinetic measurements made at the solid-liquid interface are a relative measure of surface charge and adsorption (Delgado et al. 2007; Hunter 2013). Zeta potential measurements have long been used to measure the stability of colloidal systems (Heurtault et al. 2003; Jiang et al. 2003; Hunter 2013). The colloidal system in the present study is shale dispersed in polyacrylamide. By measuring the stability of the shale system as a function of zeta potential over time, we will be able to quantify polymer-shale interaction. A comparison is made between different salt-polymer solutions (also called as shale inhibitors) for study of their role in preventing polymer adsorption on shale. Salts such as $\mathrm{KCl}$ and $\mathrm{NaCl}$ are widely used for shale inhibition (Lee et al. 2001; Patel 2009), and in the past, amines were widely used for this purpose (He et al. 2014). In this work, TMAC is compared with $\mathrm{KCl}$ and $\mathrm{NaCl}$ as an additive to anionic and cationic polyacrylamide systems for shale inhibition.

In this work, the impact of anionic and cationic polyacrylamide in injected fluids on the alteration of the surface properties of shale is studied. Using zeta potential and rheological measurements to quantify shale-polymer interaction is a novel technique and is extensively researched and studied in this work. 


\section{Materials and methods}

\subsection{Polyacrylamides}

Anionic polyacrylamide and cationic polyacrylamide with average molecular weight $10^{7} \mathrm{~g} / \mathrm{gmol}$ were obtained from Kemira Supplies. The polyacrylamides are highly water absorbent and form soft gels even at low concentration. The anionic and cationic polyacrylamide samples were measured by weight and added to deionized water slowly and mixed on a shaker table for $15 \mathrm{~min}$ at a speed of 200 RPM. The time and speed of mixing of the sample were chosen carefully so that shear damage in polyacrylamide samples was kept to a minimum before the experiments. The samples were left to hydrate for $24 \mathrm{~h}$. All of the solutions were tested within $36 \mathrm{~h}$ of preparation.

\subsection{Shale samples}

Pride Mountain and Chattanooga shale samples were prepared using a mortar and pestle. They were ground using a Bel-Art mixer to obtain smaller particles, and the sample was sieved to obtain fairly homogenous particles, with particle size smaller than $75 \mu \mathrm{m}$. The particles were small enough to remain suspended in the polymer solution and big enough to make accurate rheological measurements of slurry. The shale was kept at a constant concentration of $0.5 \mathrm{lb} / \mathrm{bbl}$ (pounds/barrel) for all of the rheology and zeta potential experiments.

\subsection{Sample information}

The Chattanooga shale sample is from an exploratory well in southwestern Tuscaloosa County, Alabama and is typical of Devonian shale reservoir rock in the eastern USA. The Pride Mountain sample is from the Gorgas \#1 borehole, which was drilled to explore the $\mathrm{CO}_{2}$ storage potential at a large coal-fired power facility in the Black Warrior Basin, Walker County, Alabama. The Pride Mountain sample is more representative of a sealing formation and is rich in expandable mixed-layer clay-wellbore stability was a significant problem during the drilling of this zone.

\subsection{Characterization of shale}

The shale samples were analyzed for clay and non-clay content by X-ray diffraction (XRD) (Clark et al. 2012) (Table 1). Other parameters such as total organic carbon (TOC), pressure decay permeability, and effective porosity were determined for both shale samples (Table 2) (Clark et al. 2012).

The whole rock mineralogy is shown in Fig. 1 as a bar graph for better understanding of the difference in mineralogy between the two shales used in this study.
Table 1 Whole rock mineralogy of shale samples determined by XRD

\begin{tabular}{lcc}
\hline Analysis & Chattanooga & Pride Mountain \\
\hline Depth, ft & 9167 & 2863 \\
Clay content, wt $\%$ & \\
Smectite & 0 & 1 \\
Illite/smectite & 5 & 16 \\
Illite + mica & 24 & 37 \\
Kaolinite & 0 & 12 \\
Chlorite & 0 & 4 \\
Non-clay mineral content, wt $\%$ & & \\
Quartz & 41 & 21 \\
K feldspar & 16 & 3 \\
Plagioclase & 2 & 2 \\
Calcite & 0 & 1 \\
Ankerite/Fe dolomite & 0 & 1 \\
Dolomite & 5 & 0 \\
Pyrite & 5 & 1 \\
Fluorapatite & 0 & 0 \\
Barite & 1 & 1 \\
Siderite & 0 & 0 \\
Magnetite & 0 & 1 \\
\hline
\end{tabular}

\subsection{Equipment}

A Discover DHR-3 stress controlled rheometer was used to make rheological measurements. Vane geometry was used for the polymer-shale samples. Vane geometry helps prevent wall slippage at higher shear rates, helps disrupt flow inhomogeneity while shearing, and also works well for samples with suspended solids (Goh et al. 2011). A coneand-plate geometry was used for polymer solutions. Coneand-plate is useful for solutions that have low viscosity and that do not have any dispersions with suspended solids larger than $64 \mu \mathrm{m}$. Cone-and-plate geometry (diameter: $60 \mathrm{~mm}$ and cone angle $2^{\circ}$ ) provides homogenous shear, shear rate, and stress in the geometry gap when used to measure the rheological properties of a solution. All the experiments were performed at a temperature of $25{ }^{\circ} \mathrm{C} \pm 0.03{ }^{\circ} \mathrm{C}$.

Since the cationic polyacrylamide can form agglomerates with shale, it is not possible to quantify the polymershale interaction rheologically. Due to agglomeration or in other words due to the flocculation of the shale particles in the solution, accurate rheological measurements cannot be made. The shale particles have to be suspended in the solution and have minimal settling velocity in order to perform rheological studies. In the cationic polyacrylamide medium, flocculation can result in excessive gravitational settling of the agglomerated shale particles. Hence, only 
Table 2 TOC, effective porosity and pressure decay permeability

\begin{tabular}{llc}
\hline Parameters & Chattanooga & Pride Mountain \\
\hline TOC, wt\% & 3.33 & 0.80 \\
Effective porosity, \% of bulk volume & 2.32 & 12.30 \\
Pressure decay permeability, mD & 0.00032 & 0.00048 \\
\hline
\end{tabular}
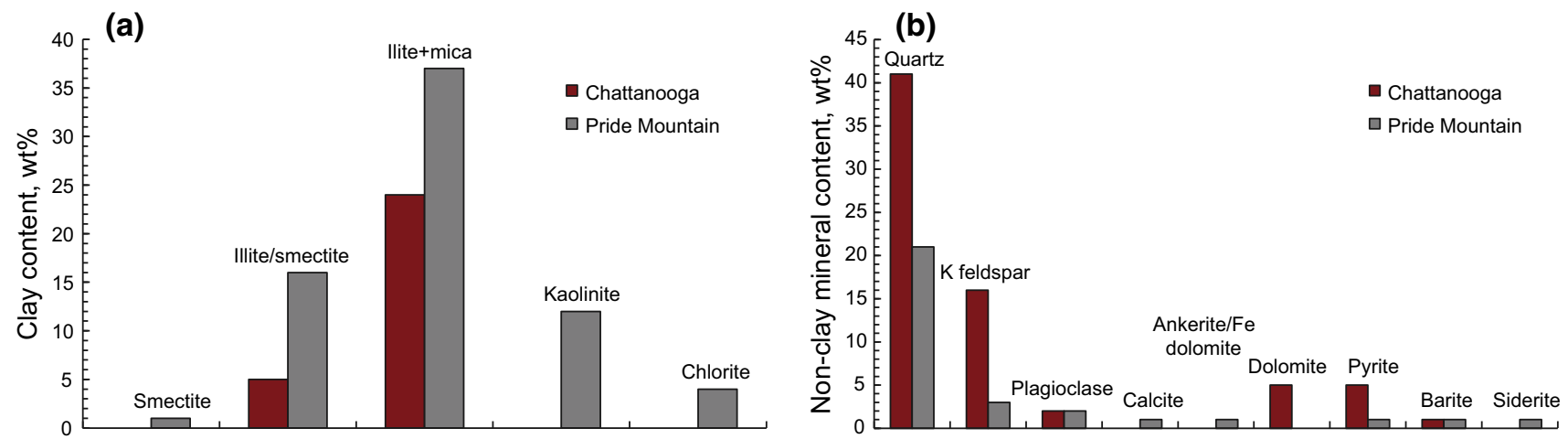

Fig. 1 a Percentage of clay content in Chattanooga and Pride Mountain shale, b Percentage of non-clay mineral content in Chattanooga and Pride Mountain shale

the anionic polyacrylamide was used to rheologically quantify polymer-shale interaction. However, both cationic and anionic polyacrylamides were used to quantify polymer-shale zeta potential. The anionic polyacrylamide concentration was $0.1-0.2 \mathrm{wt} \%$, such that the concentration is well above $C^{*}$ (critical overlap concentration) and below $C^{* *}$ (critical entanglement concentration). The concentration of shale was kept constant at $0.5 \mathrm{lb} / \mathrm{bbl}$, and the concentration of anionic polyacrylamide was varied from 0.1 to $0.2 \mathrm{wt} \%$.

Figure 2 shows the experimental setup, including the cone-and-plate and vane geometry.

\subsection{Zeta potential analyzer}

A phase analysis light scattering technique (PALS) is used to measure the zeta potential of polyacrylamide-shale interfaces. A Zeta PALS measurement system manufactured by Brookhaven Instruments Corporation (Holtsville, NY) was used. The experiments were conducted at $25^{\circ} \mathrm{C}$ in triplicate. A platinum electrode and $\mathrm{H}-\mathrm{Ne}$ laser light source were used to measure the electrophoretic mobility of colloidal suspensions. The polyacrylamide-shale sample was prepared by adding polyacrylamide to deionized (DI) water, and it was kept on a shaker table at a speed of 200 RPM for $15 \mathrm{~min}$. The shale sample was weighed and added to DI water. Both samples were left to hydrate at room temperature for $24 \mathrm{~h}$. The shale particles were filtered using a $1-\mu \mathrm{m}$ syringe filter and added to the polyacrylamide sample. The solution was shaken and added to the cuvette using a pipette. The size of the shale particles is in the colloidal range $\left(1 \times 10^{-9} \mathrm{~m}\right)$, in which physiochemical forces such as van der Waals attractive forces and double layer repulsive forces are stronger than gravitational forces (Kaya et al. 2003). Figure 3 shows the particle size distribution of shale particles before filtering it to get particle sizes lesser than $1 \mu \mathrm{m}$.

A $1-\mathrm{cm}^{3}$ sample was used for all the measurements, and the tip of the cuvette was immersed in the sample to prevent formation of air bubbles. The Pt electrode was then placed in the cuvette, and the zeta potential measurements were recorded. In order to study the influence of salt on polymer-shale interaction, salt solutions of $\mathrm{KCl}, \mathrm{NaCl}$ and TMAC were used. To study the increase in average particle size with time, dynamic light scattering using the Zeta PALS was used. A $0.45-\mu \mathrm{m}$ syringe filter was used to filter dust from the samples before loading the sample to the Zeta PALS. A zeta potential measurement was recorded every $20 \mathrm{~min}$ and for each data point, ten readings were taken, and the average effective diameter and the associated standard error were plotted vs. time. The compositions of the various suspensions used are given in Table 3. The composition of the suspension was chosen such that the salt concentration met the Zeta PALS instrument specification, and the polyacrylamide concentration, which was just enough to keep the shale suspended in the polyacrylamide, was chosen.

\subsection{Analysis with the Carreau model}

In order to determine the zero shear rate viscosity of the fluid, the Carreau model was used. This model describes a 

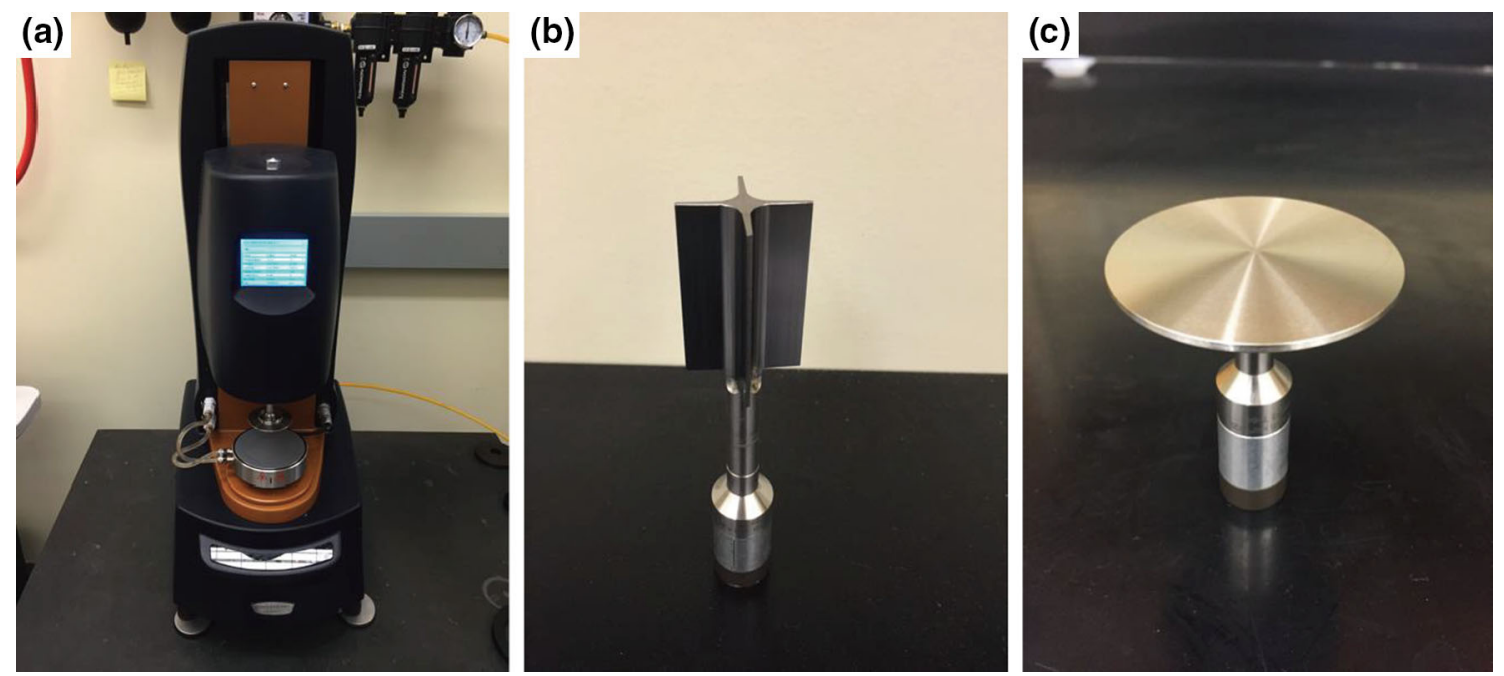

Fig. 2 a DHR-3 Rheometer. b Vane geometry. c Cone-and-plate geometry

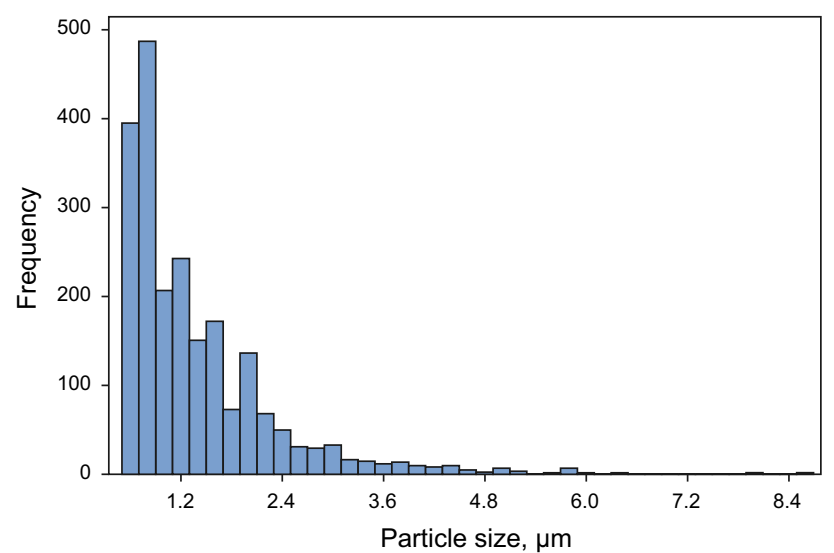

Fig. 3 Histogram of particle size distribution of shale particles used in the study

Table 3 Compositions of different suspension media used in the study

\begin{tabular}{ll}
\hline Sample & Medium \\
\hline 1 & $0.05 \mathrm{wt} \%$ anionic polyacrylamide \\
2 & $0.05 \mathrm{wt} \%$ cationic polyacrylamide \\
3 & $0.05 \mathrm{wt} \%$ anionic polyacrylamide $+0.05 \mathrm{wt} \% \mathrm{KCl}$ \\
4 & $0.05 \mathrm{wt} \%$ cationic polyacrylamide $+0.05 \mathrm{wt} \% \mathrm{KCl}$ \\
5 & $0.05 \mathrm{wt} \%$ anionic polyacrylamide $+0.05 \mathrm{wt} \% \mathrm{NaCl}$ \\
6 & $0.05 \mathrm{wt} \%$ cationic polyacrylamide $+0.05 \mathrm{wt} \% \mathrm{NaCl}$ \\
7 & $0.05 \mathrm{wt} \%$ anionic polyacrylamide $+0.05 \mathrm{wt} \% \mathrm{TMAC}$ \\
8 & $0.05 \mathrm{wt} \%$ cationic polyacrylamide $+0.05 \mathrm{wt} \% \mathrm{TMAC}$ \\
\hline
\end{tabular}

wide range of non-Newtonian behavior by curve fitting within the Newtonian and the shear thinning non-Newtonian regions (Rao 2014). This model can be applied over a wide range of shear rates. The Carreau model is a variant of

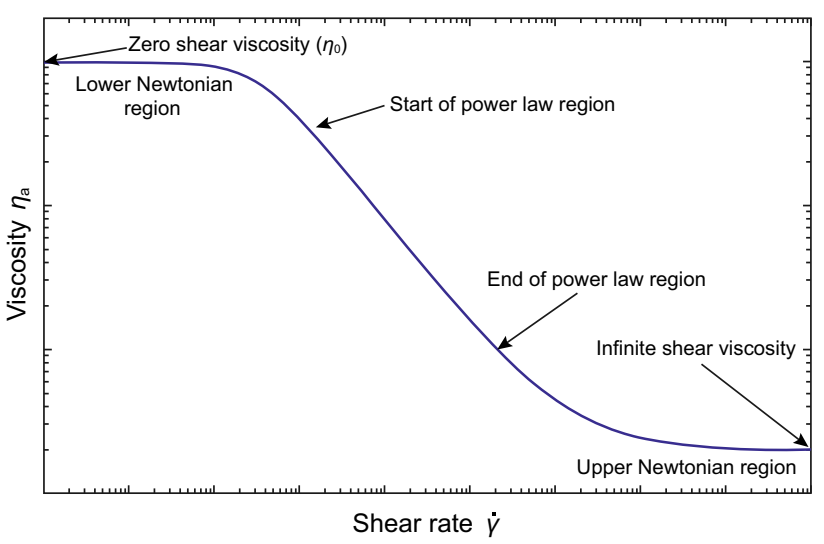

Fig. 4 Carreau model logarithmic fit for viscosity versus shear rate

the Cross model and is used for logarithmic data sets. This viscosity model allows data to be fitted to the following model,

$\frac{\eta-\eta_{\infty}}{\eta_{0}-\eta_{\infty}}=\frac{1}{\left(1+(\lambda \dot{\gamma})^{2}\right)^{n / 2}}$

where $\eta_{0}$ the Newtonian viscosity, $\eta_{\infty}$ the infinite viscosity, $\dot{\gamma}$ the shear rate, $\lambda$ the relaxation time, and $n$ the power law index.

Figure 4 shows the plot of apparent viscosity vs. shear rate for a shear thinning Carreau fluid identifying three separate regions. The zero shear viscosity represents the lower Newtonian region at lower shear rates; the infinite shear viscosity captures the higher shear rate, which is the upper Newtonian region; the power law region is characterized by the power law index and the relaxation time which gives the time estimate, at which the lower Newtonian region ends. 


\section{Results and discussion}

\subsection{Characterizing polymer-shale interaction through zeta potential measurements}

Zeta potential measurements were made for Pride Mountain and Chattanooga shale samples in different suspending media to quantify the polyacrylamide-shale interaction. The measured zeta potential is a function of the surface charge of the suspended particle, any adsorbed layer at the particle-liquid interface, and the nature and composition of the surrounding medium (Jia and Williams 1990). For the same experimental conditions, the change in zeta potential over time is indicative of polymer adsorption on shale. The higher the absolute values of negative zeta potential, the bigger the double layer thickness of the shale particle. Higher negative zeta potential value is also indicative of swelling and dispersion of clay (Zhong et al. 2011). The zeta potential values measured for the shale samples were $\sim-24 \mathrm{mV}$ for both Chattanooga and Pride Mountain shale.

The zeta potential of cationic and anionic polyacrylamide with Chattanooga and Pride Mountain shale was measured immediately after adding the shale sample to the polyacrylamide sample. In cationic polyacrylamide (with no salts), there was not a significant difference in zeta potential values for the shales, whereas in the presence of salts ( $\mathrm{KCl}$ and $\mathrm{NaCl}$ ) or TMAC (Fig. 5), Chattanooga shale had higher zeta potential values which is indicative of higher polyacrylamide adsorption density than Pride Mountain shale. Similarly in anionic polyacrylamide, Pride Mountain shale had higher absolute zeta potential values in the presence of $\mathrm{KCl}$ and TMAC, indicative of higher polyacrylamide adsorption density (Fig. 6). The change in zeta potential with time for the same system will be discussed in the following sections.

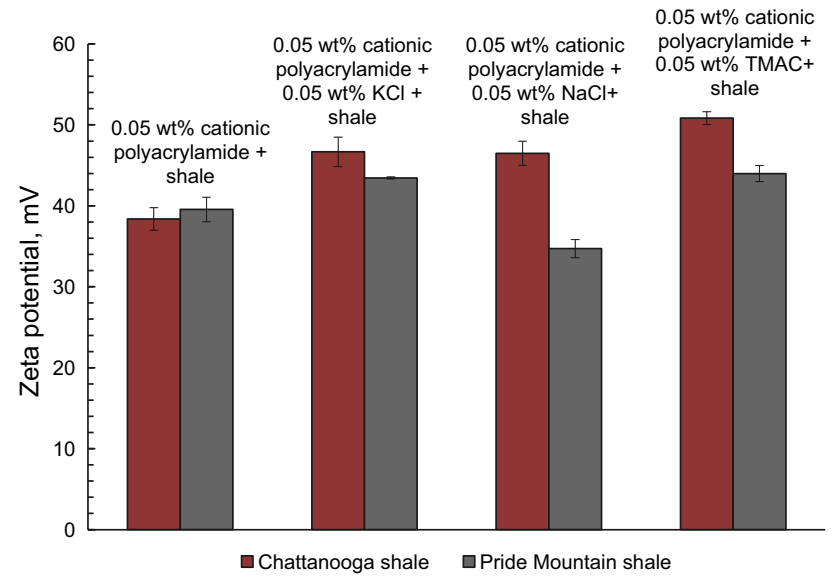

Fig. 5 Change of zeta potential of shales in cationic polyacrylamide with salts or TMAC
In order to determine the influence factor for polymer adsorption on shale, the change in zeta potential with time was investigated. It is important to measure the zeta potential of the shale-free polymer solution as a control. Polyacrylamides were stable for $48 \mathrm{~h}$ from preparation of the sample. Figures 7 and 8 show the zeta potential measured over time for anionic and cationic polyacrylamide with no shale.

The zeta potential remained almost constant over time (Figs. 7, 8). This proved that the polyacrylamide remained stable during the time of experiment and the change in zeta potential after adding shale to the polymer was solely because of the changes in the surface properties of shale when in contact with polyacrylamide.

Figures 9 and 10 show the change in zeta potential with time for Chattanooga shale incubated in different media containing anionic and cationic polyacrylamide, respectively. A dotted line is drawn at $20 \mathrm{mV}$ (Figs. 10, 12) to show the point below which the colloidal system is unstable due to flocculation.

Figures 11 and 12 show the change in zeta potential with time for Pride Mountain shale in different media containing anionic and cationic polyacrylamide, respectively.

In the absence of salt, the overall magnitude (i.e., absolute value) of the zeta potential increased for both shale samples in anionic polyacrylamide (Figs. 9, 11) and decreased in cationic polyacrylamide (Figs. 10, 12). In cationic polyacrylamide, the decrease in zeta potential of shale with polymer adsorption is due either to a decrease in charge density or a shift in the shear plane. The zeta potential also decreases more rapidly when the double layer is compressed at high ionic strength (Brooks and Seaman 1973; Vane and Zang 1997). The hydrophilic ends of the cationic polyacrylamide attached themselves to the positively charged edges of clay particles and cause bridging of clay particles. This created clusters of large particles to resist flow and lead to decrease in mobility and zeta potential (Yalçın et al. 2002). Addition of salts

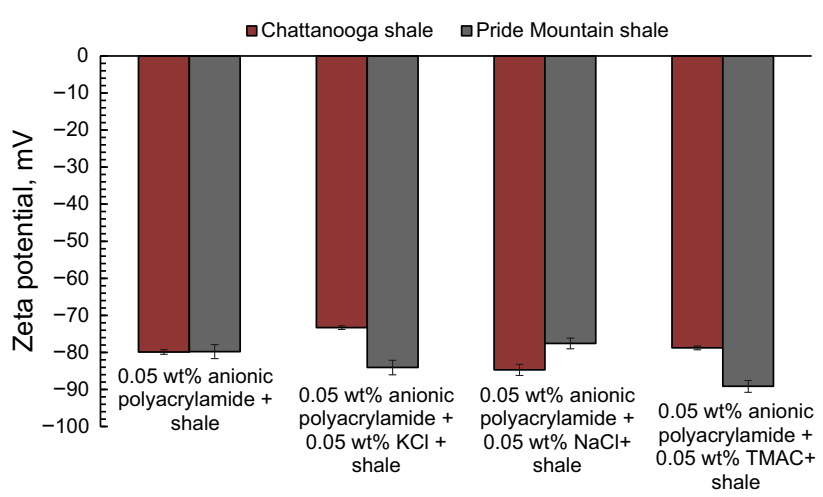

Fig. 6 Change of zeta potential of shales in anionic polyacrylamide with salts or TMAC 


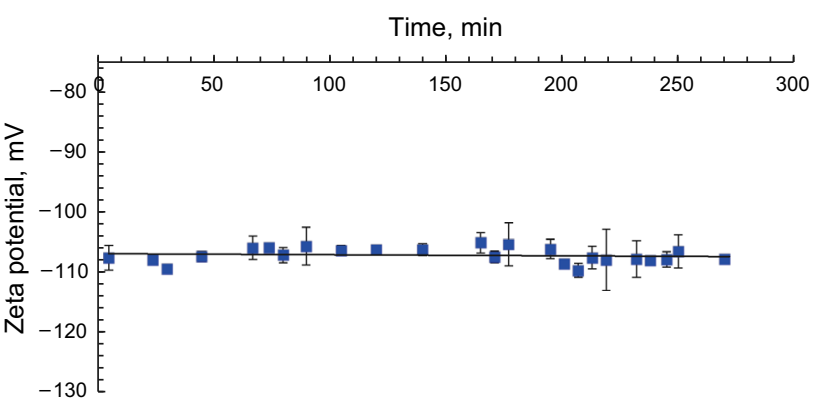

Fig. 7 Zeta potential versus time for anionic polyacrylamide

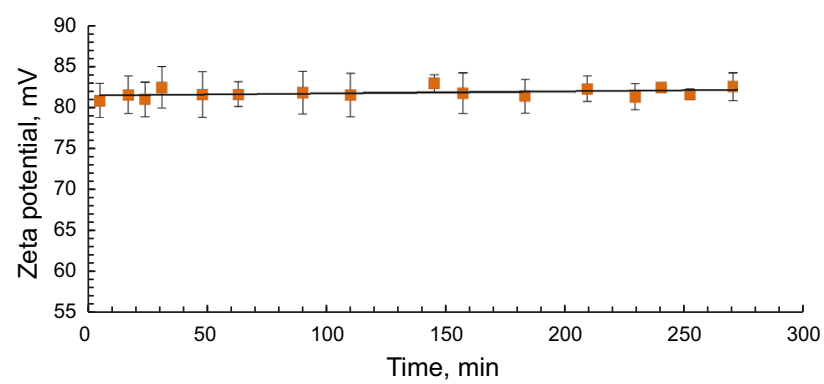

Fig. 8 Zeta potential versus time for cationic polyacrylamide

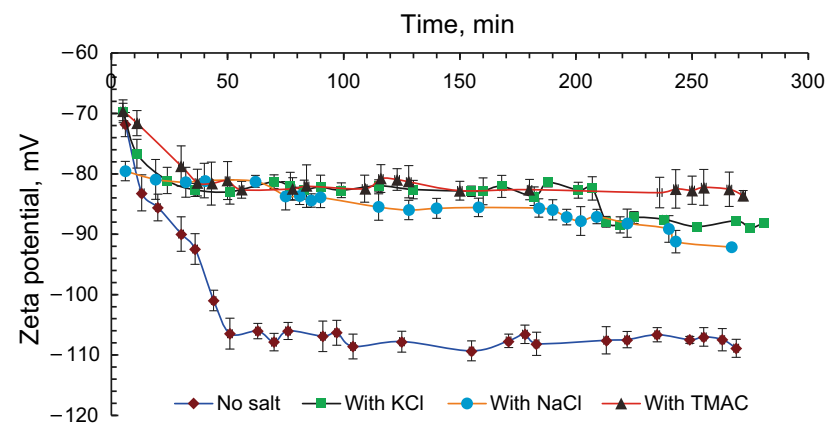

Fig. 9 Zeta potential of Chattanooga shale incubated with anionic polyacrylamide under various conditions

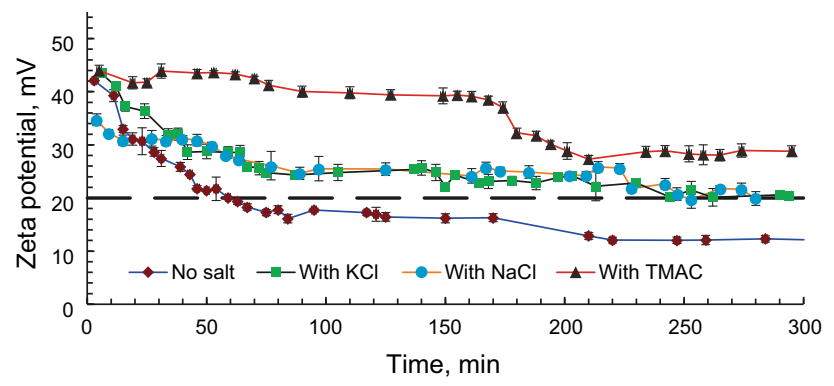

Fig. 10 Zeta potential of Chattanooga shale incubated with cationic polyacrylamide under various conditions

increased the net positive charge of the medium, leading to the increase in zeta potential. Zeta potential values between $-20 \mathrm{mV}$ and $20 \mathrm{mV}$ had an effective charge low enough for flocculation to occur (Johnson et al. 2010).

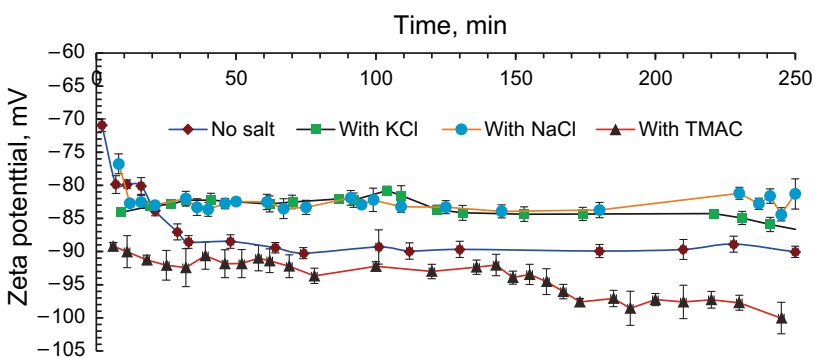

Fig. 11 Zeta potential of Pride Mountain shale incubated with anionic polyacrylamide under various conditions

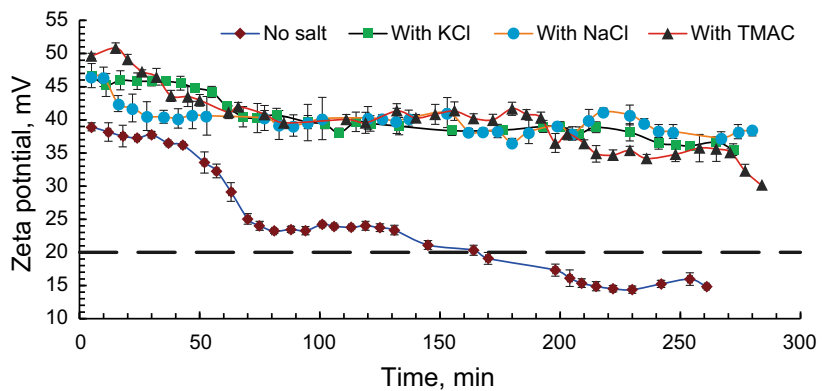

Fig. 12 Zeta potential of Pride Mountain shale incubated with cationic polyacrylamide under various conditions

Colloidal particles in suspension either flocculate or deflocculate depending on which force predominates, the van der Waals attractive force or the double layer repulsive force (Street and Wang 1966). In the absence of salt, cationic polyacrylamide caused flocculation of shale particles with time because the attractive forces predominated. Since there was rapid flocculation as the shale came in contact with cationic polyacrylamide, it was difficult to determine whether adsorption density increased with time. Additional studies will need to be performed with cationic polyacrylamide and shale to determine the effect of adsorption on zeta potential. The observed flocculation was a sign of strong interaction of polymer with shale, and the addition of salt inhibited flocculation.

In the anionic polyacrylamide system for Chattanooga and Pride Mountain shale, there is an increase in the absolute value of the zeta potential with time. This is indicative of the increase in the double layer thickness, which, in turn, is due to increasing adsorption density of polyacrylamide. In the Chattanooga shale, the absence of salt causes the absolute value of the zeta potential to increase to a point and then level off. Salt helps to decrease the ionic nature of clay and thus leaves fewer sites remaining for the polymer to adsorb (Menon and Wasan 1987a; Kulshrestha et al. 2004). In previous work, it has been shown that salts such as $\mathrm{KCl}$ minimize clay hydration and swelling, thereby minimizing the interaction of shale with fluid (van Oort 1994; Patel et al. 2001; van Oort 2003; 
Patel 2009; Anderson et al. 2010; Lane and Aderibigbe 2013). However, with Pride Mountain shale, the zeta potential values are higher in the presence of TMAC. This is attributed to both the shale and the polyacrylamide having predominantly negative surface charge, which leads to an overall increase in charge of the system and also the Pride Mountain shale (being rich in smectites) has more exchangeable sodium ions. Ammonium ions from TMAC exchange with smaller sodium ions; ammonium with its larger hydration radius increases the swelling leading to an increase in zeta potential values.

The zeta potential of Chattanooga and Pride Mountain shales was measured in different saline media before adding the anionic and cationic polyacrylamide. Figure 13 shows the increase in the absolute value of the zeta potential after adding the anionic polyacrylamide to the shale-salt solution (i.e., the difference in the value of zeta potential before and after adding anionic polyacrylamide). In anionic polyacrylamide, $\mathrm{KCl}$ was the most effective shale inhibitor followed by TMAC and $\mathrm{NaCl}$ for Chattanooga shale. For Pride Mountain shale, $\mathrm{KCl}$ also was the most effective shale inhibitor, but $\mathrm{NaCl}$ was slightly more effective than TMAC. The reason for $\mathrm{KCl}$ providing better inhibition was because potassium ions have a smaller hydration radius and can easily exchange with the more swellable sodium ions on shale surface and due to their small hydration radius, they reduce swelling and provide better shale inhibition.

In order to observe flocculation of shale with cationic polyacrylamide, particle size measurements were made with time for the Pride Mountain shale-cationic polyacrylamide system. Figure 14 shows the increase in effective diameter of the shale particles with time. The system became unstable after $120 \mathrm{~min}$ because of flocculation and particle settling.

As shown in Fig. 14, the effective diameter increased with time indicative of flocculation.

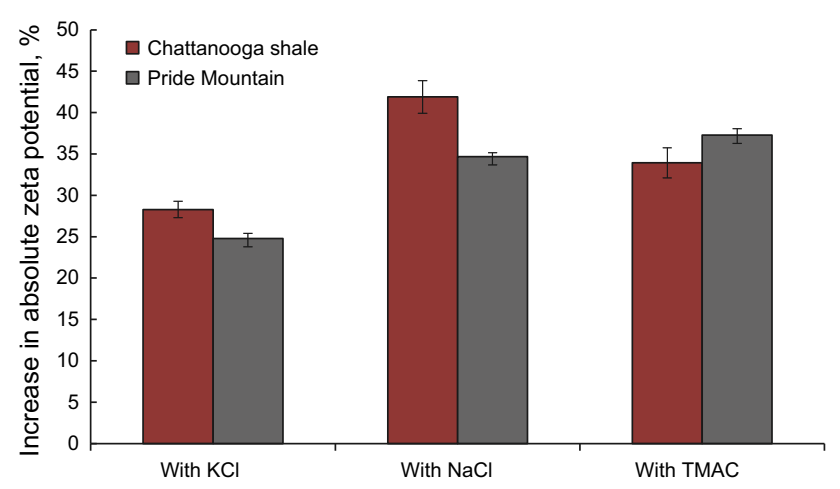

Fig. 13 Increase in zeta potential for shale in anionic polyacrylamide with salt and TMAC
The results are in agreement with previous work on the effect of adsorption density on zeta potential. As adsorption density increases, the zeta potential of the shale polyacrylamide complex increases and then levels off when the adsorption density approaches capacity (Menon and Wasan 1987a). In the presence of cationic polyacrylamide, by contrast, the absolute value of zeta potential decreases due to flocculation. In summary, salt tends to decrease the adsorption density of polymer on clay surfaces and leaves fewer active sites on the clay surfaces for the polyacrylamides to interact.

\subsection{Rheological study of polymer-shale interaction}

In this section, we discuss the rheology of the anionic and cationic polyacrylamide before and after adding the ground shale particles. The interaction of anionic polyacrylamide with the different shale samples was plotted as a function of anionic polyacrylamide concentration. The concentration of shale was kept constant at $0.5 \mathrm{lb} / \mathrm{bbl}$, and the concentration of anionic polyacrylamide was varied from 0.1 to $0.2 \mathrm{wt} \%$. The change in zero shear rate viscosity for the change in anionic polyacrylamide concentration is shown in Fig. 15.

Figure 15 demonstrates that each shale interacts differently with anionic polyacrylamide. The Chattanooga shale sample has the highest viscosity in a given polyacrylamide concentration, and the Pride Mountain sample has the lowest viscosity. Usually the sample with highest viscosity is considered to have strong interaction of the bulk fluid with the shale particles, but in this case, the viscosity decreases after adding the shale to the polyacrylamide, i.e., polyacrylamides without shale have higher viscosity values at a given polyacrylamide concentration. This was indicative that the polyacrylamides adsorbing onto the shale and leaving the solution are causing the decrease in the viscosity. Hence, Pride Mountain shale has stronger interactions with anionic polyacrylamide.

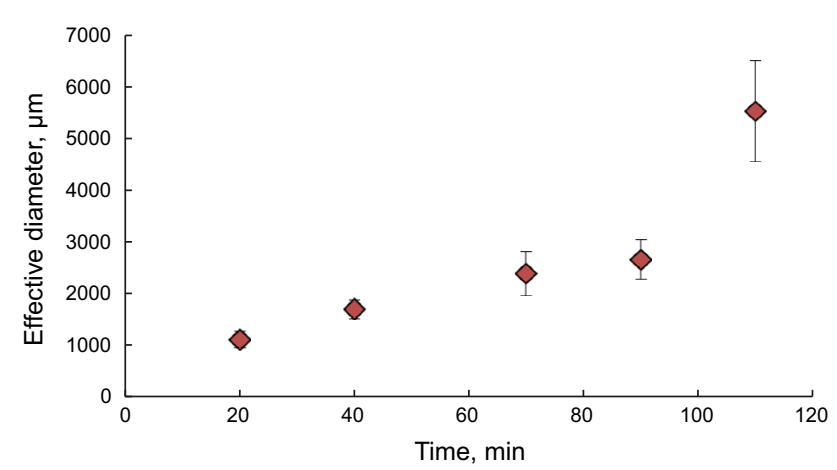

Fig. 14 Flocculation of Pride Mountain shale in the presence of cationic polyacrylamide as measured by dynamic light scattering 


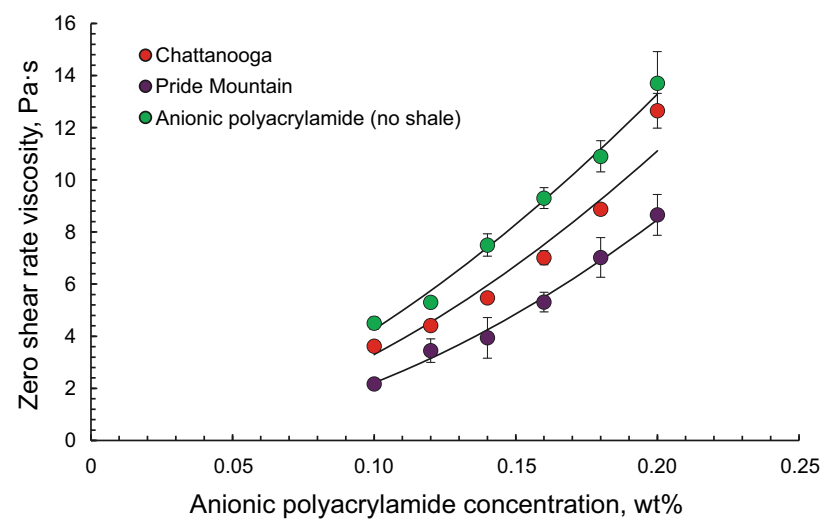

Fig. 15 Change in zero shear rate viscosity with increasing anionic polyacrylamide concentration for Chattanooga and Pride Mountain shale

In order to determine the change in viscosity of the shale-polymer samples with time, flow ramp tests were conducted on the samples for 5 days at equal intervals. The concentration of the anionic polyacrylamide and shale was kept constant at $0.16 \mathrm{wt} \%$ and $0.5 \mathrm{lb} / \mathrm{bbl}$, respectively. After taking the first reading, the sample was left undisturbed in the geometry for few hours before the next reading. The sample was manually stirred in order to suspend the shale particles in the anionic polyacrylamide sample before starting the experiment. Figure 16 shows the change in viscosity of the shale-polymer sample with time.

The viscosity curve (Fig. 16) follows the same trend for both Pride Mountain and Chattanooga shales. After $2000 \mathrm{~min}$, the viscosity remains constant. This signifies the point at which the clay particles have reached saturation in the anionic polyacrylamide solution. The percentage of reduction of viscosity was approximately same for both the shales at the end of Day 5, which is $\sim 34 \%$. The polyacrylamide was adsorbed onto the surface of shale particles, which leads to decreasing viscosity with time.

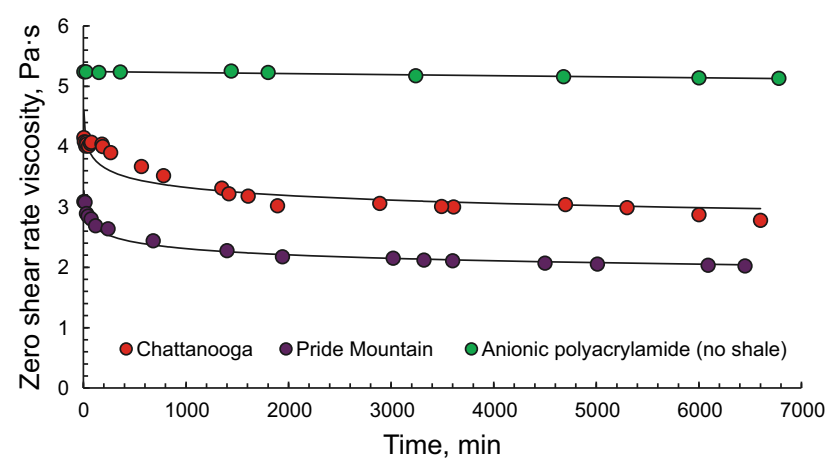

Fig. 16 Change in zero shear rate viscosity with time of Chattanooga and Pride Mountain shale in anionic polyacrylamide
Interestingly, the viscosity of the anionic polyacrylamide remains unchanged for the same experimental conditions, which proves that the anionic polyacrylamide remains stable over course of the experiment. In comparison with the zeta potential tests, rheological studies were easier to perform and the results are easier to interpret. Simple rheological methods like this can be used to assess shalefluid interaction qualitatively.

\section{Conclusion}

A method was developed to characterize polyacrylamideshale interaction. Zeta potential and rheological measurements were made to semi-quantify these interactions. Based on the studies, cationic polyacrylamide interacts with both the shales strongly even in the presence of salt and TMAC, whereas anionic polyacrylamide interacts less with the shales. Each type of shale analyzed interacts differently with polyacrylamide. All samples interact strongly with cationic polyacrylamide because of the negative surface charge on clay platelets. It is recommended to use anionic polyacrylamide because of its minimal interaction and also compatibility with other fluid additives. Due to the cationic polyacrylamides interacting strongly with shale, it can potentially cause formation damage. Both the rheological studies and the zeta potential tests gave the same results. Rheological methods are easier to perform and require less time compared to zeta potential experiments and can be used for qualitative understanding of shale-fluid interaction while zeta potential tests can be used for semiquantitative understanding alterations to shale surface when in contact with different fluids. It is imperative to understand fluidrock interaction extensively, and this is especially true for polyacrylamide. Additives that are widely used as good shale inhibitors for one formation need not necessarily work well for another formation. For instance, in this study TMAC was an effective inhibitor for Chattanooga shale but increased swelling in Pride Mountain shale. This study reiterates the importance of testing shale for additives that can cause wellbore instability before injecting the fluids. Further studies are being performed to model the polymer-shale interaction and to identify additives that would facilitate effective friction reduction while minimizing these interactions.

Open Access This article is distributed under the terms of the Creative Commons Attribution 4.0 International License (http://crea tivecommons.org/licenses/by/4.0/), which permits unrestricted use, distribution, and reproduction in any medium, provided you give appropriate credit to the original author(s) and the source, provide a link to the Creative Commons license, and indicate if changes were made. 


\section{References}

Aften C, Watson WP. Improved friction reducer for hydraulic fracturing. SPE Hydraul Fract Technol Conf, The Woodlands, Texas, Soc Pet Eng. 2009. doi:10.2118/118747-MS.

Al-Bazali TM. Experimental study of the membrane behavior of shale during interaction with water-based and oil-based muds. Dissertation, University of Texas; 2005.

Anderson RL, Ratcliffe I, Greenwell HC, et al. Clay swelling-a challenge in the oilfield. Earth Sci Rev. 2010;98(3):201-16. doi:10.1016/j.earscirev.2009.11.003.

Brooks DE, Seaman GVF. The effect of neutral polymers on the electrokinetic potential of cells and other charged particles: I. Models for the zeta potential increase. J Colloid Interface Sci. 1973;43(3):670-86. doi:10.1016/0021-9797(73)90413-X.

Carman PS, Cawiezel K. Successful breaker optimization for polyacrylamide friction reducers used in slickwater fracturing. SPE Hydraul Fract Technol Conference, College Station, Texas, Soc Pet Eng. 2007. doi:10.2118/106162-MS.

Clark P, Pashin J, Carlson E, et al. Site Characterization for $\mathrm{CO}_{2}$ Storage from Coal-fired Power Facilities in the Black Warrior Basin of Alabama, University Of Alabama. DOE report. 2012.

Delgado ÁV, González-Caballero F, Hunter RJ, et al. Measurement and interpretation of electrokinetic phenomena. J Colloid Interface Sci. 2007;309(2):194-224. doi:10.1016/j.jcis.2006. 12.075 .

Ghassemi A, Diek A. Linear chemo-poroelasticity for swelling shales: theory and application. J Pet Sci Eng. 2003;38(3):199-212. doi:10.1016/S0920-4105(03)00033-0.

Goh R, Leong Y-K, Lehane B. Bentonite slurries-zeta potential, yield stress, adsorbed additive and time-dependent behaviour. Rheol Acta. 2011;50(1):29-38. doi:10.1007/s00397-010-0498-x.

Gomez SL, He W. Fighting wellbore instability: customizing drilling fluids based on laboratory studies of shale-fluid interactions. IADC/SPE Asia Pac Drill Technol Conf Exhib Tianjin, China, Soc Pet Eng. 2012. doi:10.2118/155536-MS.

Harris PC. Fracturing-fluid additives. J Pet Technol. 1988;40(10):1277-279. doi:10.2118/17112-PA.

He W, Gomez SL, Leonard RS, et al. Shale-fluid interactions and drilling fluid designs. IPTC 2014: International Petroleum Technology Conference. 2014. 19-22 Jan, Doha, Qatar.

Heurtault B, Saulnier P, Pech B, et al. Physico-chemical stability of colloidal lipid particles. Biomaterials. 2003;24(23):4283-300. doi:10.1016/S0142-9612(03)00331-4.

Horsrud P, Bostrom B, Sonstebo EF, et al. Interaction between shale and water-based drilling fluids: laboratory exposure tests give new insight into mechanisms and field consequences of $\mathrm{KCl}$ contents. SPE Annu Tech Conf Exhib Soc Pet Eng. 1998. doi:10. 2118/48986-MS.

Hunter RJ. Zeta potential in colloid science: Principles and applications. Cambridge: Academic Press; 2013.

Jia X, Williams RA. Particle deposition at a charged solid/liquid interface. Chem Eng Commun. 1990;91(1):127-98. doi:10.1080/ 00986449008940706.

Jiang L, Gao L, Sun J. Production of aqueous colloidal dispersions of carbon nanotubes. J Colloid Interface Sci. 2003;260(1):89-94. doi:10.1016/S0021-9797(02)00176-5.

Johnson JD, Schoppa D, Garza JL, et al. Enhancing Gas and Oil Production With Zeta Potential Altering System. SPE Int Symp Exhib Form Damage Control, Lafayette, Louisiana, Soc Pet Eng. 2010. doi:10.2118/128048-MS

Kaya A, Oren A H, Yukselen Y. Settling behavior and zeta potential of kaolinite in aqueous media. The Thirteenth International Offshore and Polar Engineering Conference, Honolulu, Hawaii, International Society of Offshore and Polar Engineers. 2003.
Khodja M, Canselier JP, Bergaya F, et al. Shale problems and waterbased drilling fluid optimisation in the Hassi Messaoud Algerian oil field. Appl Clay Sci. 2010;49(4):383-93. doi:10.1016/j.clay. 2010.06.008

Kulshrestha P, Giese RF, Aga DS. Investigating the molecular interactions of oxytetracycline in clay and organic matter: insights on factors affecting its mobility in soil. Environ Sci Technol. 2004;38(15):4097-105. doi:10.1021/es034856q.

Lal M. Shale stability: drilling fluid interaction and shale strength. SPE Asia Pac Oil and Gas Conf Exhib Jakarta, Indonesia Soc Pet Eng. 1990. doi:10.2118/54356-MS.

Lane RH, Aderibigbe AA. Rock/fluid chemistry impacts on shale fracture behavior. SPE Int Symp Oilfield Chem Soc Pet Eng. 2013. doi:10.2118/164102-MS.

Lee L, Patel A D, Stamatakis E. Glycol based drilling fluid. 2001; US Patent No 6291405.

$\mathrm{Lu}$ CF. A new technique for the evaluation of shale stability in the presence of polymeric drilling fluid. SPE Prod Eng. 1988;3(03):366-74. doi:10.2118/14249-PA.

Luckham PF, Rossi S. The colloidal and rheological properties of bentonite suspensions. Adv Colliod Interface Sci. 1999;82(1):43-92. doi:10.1016/S0001-8686(99)00005-6.

Mahto V, Sharma VP. Rheological study of a water based oil well drilling fluid. J Pet Sci Eng. 2004;45(1-2):123-8. doi:10.1016/j. petrol.2004.03.008.

Menon VB, Wasan DT. Adsorption of maltenes on sodium montmorillonite. Colloids Surf. 1987a;25(2-4):387-92. doi:10.1016/ 0166-6622(87)80316-5.

Menon VB, Wasan DT. Particle-fluid interactions with applications to solid-stabilized emulsions Part III. Asphaltene adsorption in the presence of quinaldine and 1,2-dimethylindole. Colloids Surf. 1987b;23(4):353-62. doi:10.1016/0166-6622(87)80276-7.

Mody FK, Hale AH. Borehole-stability model to couple the mechanics and chemistry of drilling-fluid/shale interactions. J Pet Technol. 1993;45(11):1093-101. doi:10.2118/25728-PA.

Mody FK, Tare UA, Tan CP, et al. Development of novel membrane efficient water-based drilling fluids through fundamental understanding of osmotic membrane generation in shales. SPE Annu Tech Conf Exhib San Antonio, Texas, Soc Pet Eng. 2002. doi:10.2118/77447-MS.

Mueller S, Llewellin EW, Mader HM. The rheology of suspensions of solid particles proceedings: mathematical. Phys Eng Sci. 2010;466(2116):1201-28. doi:10.1098/rspa.2009.0445.

Muniz ES, Fontoura SAB, Lomba RFT. Rock-drilling fluid interaction studies on the diffusion cell. SPE Latin American and Caribbean Pet Eng Conf, Rio de Janeiro, Brazil, Soc Pet Eng. 2005. doi:10.2118/94768-MS.

Patel AD. Design and development of quaternary amine compounds: shale inhibition with improved environmental profile. SPE Int Symp Oilfield Chem, Soc Pet Eng. 2009. doi:10.2118/121737-MS.

Patel A D, Stamatakis E, Davis E. Shale hydration inhibition agent and method of use; US Patent 6247543. (2001).

Petersen PB, Saykally RJ. Is the liquid water surface basic or acidic? macroscopic vs. molecular-scale investigations. Chem Phys Lett. 2008;458(4):255-61. doi:10.1016/j.cplett.2008.04.010.

Rao MA. Flow and functional models for rheological properties of fluid foods. Rheology of fluid, semisolid, and solid foods. Berlin: Springer; 2014. p. 27-61.

Street N, Wang F D.(1966) Surface potentials and rock strength. 1st ISRM Congress, Lisbon, Portugal, International Society for Rock Mechanics.

Tan CP, Richards BG, Rahman SS. Managing physico-chemical wellbore instability in shales with the chemical potential mechanism. SPE Asia Pac Oil and Gas Conf, Adelaide, Australia, Soc Pet Eng. 1996. doi:10.2118/36971-MS. 
van Olphen H. An introduction to clay colloid chemistry. 2nd ed. Hoboken: Wiley; 1977.

van Oort E. A novel technique for the investigation of drilling fluid induced borehole instability in shales. Rock Mech Pet Eng, Delft, Netherlands, Soc Pet Eng. 1994. doi:10.2118/28064-MS.

van Oort E. On the physical and chemical stability of shales. J Pet Sci Eng. 2003;38(3):213-35. doi:10.2118/28064-MS.

van Oort E, Hale AH, Mody FK. Manipulation of coupled osmotic flows for stabilisation of shales exposed to water-based drilling fluids. SPE Annu Tech Conf Exhib, Dallas, Texas, Soc Pet Eng. 1995. doi:10.2118/30499-MS.

Vane LM, Zang GM. Effect of aqueous phase properties on clay particle zeta potential and electro-osmotic permeability: implications for electro-kinetic soil remediation processes. J Hazard Mater. 1997;55(1-3):1-22. doi:10.1016/S03043894(97)00010-1.

Werner C, Zimmermann R, Kratzmüller T. Streaming potential and streaming current measurements at planar solid/liquid interfaces for simultaneous determination of zeta potential and surface conductivity. Colloids Surf A. 2001;192(1):205-13. doi:10.1016/ S0927-7757(01)00725-7.

Yalçın T, Alemdar A, Ece ÖI, et al. The viscosity and zeta potential of bentonite dispersions in presence of anionic surfactants. Mater Lett. 2002;57(2):420-4. doi:10.1016/S0167-577X(02)00803-0.

Yu M, Chenevert ME, Sharma MM. Chemical-mechanical wellbore instability model for shales: accounting for solute diffusion. J Pet Sci Eng. 2003;38(3):131-43. doi:10.1016/S09204105(03)00027-5.

Zhang J, Al-Bazali TM, Chenevert ME, et al. Sharma factors controlling the membrane efficiency of shales when interacting with water-based and oil-based muds. Int Oil and Gas Conf Exhib China, Beijing, China, Soc Pet Eng. 2006. doi:10.2118/ 100735-MS.

Zhong H, Qiu Z, Huang W, et al. Shale inhibitive properties of polyether diamine in water-based drilling fluid. J Pet Sci Eng. 2011;78(2):510-5. doi:10.1016/j.petrol.2011.06.003. 